\title{
Synthesis of nanoporous chromium film by DC electrodeposition on aluminum substrate
}

\author{
Mohamed Shaban ${ }^{\mathrm{a},{ }^{*}}$, Ashour M. Ahmed ${ }^{\mathrm{a}}$, Ehab Abdel-Rahman ${ }^{\mathrm{b}}$, and \\ Hany S. Hamdy ${ }^{\text {a }}$ \\ ${ }^{a}$ Nanophotonics and Applications (NPA)Lab, Department of Physics, Faculty of Science, Beni-Suef University, \\ Beni-Suef 62514, Egypt. \\ ${ }^{b}$ Yousef Jameel Science and Technology Research Center, American University in Cairo, New Cairo, Cairo \\ 11835, Egypt.
}

\begin{abstract}
Porous Anodic Alumina (PAA) is widely employed as a template for fabrication of nanostructures due to its ability to generate self-organized, well-ordered pore structures. A new technique has been developed to deposit porous Chromium (Cr) film on Al substrate by DC electrodeposition. The chemical composition and morphological characteristics of fabricated PAA membrane and Cr film were investigated by scanning electron microscopy (SEM), and energy-dispersive $x$-ray spectroscopy (EDX). In addition, the growth mechanism of the fabricated nanoporous Cr film was discussed.

Keywords: Nanoporous Cr film; PAA membrane; DC electrochemical deposition; Growth mechanism
\end{abstract}

\section{Introduction}

The development of porous materials with large specific surface areas is currently an area of extensive research; particularly with regard to potential applications in areas such as adsorption, chromatography, catalysis, sensor technology, optoelectronic systems, and gas storage [1-4]. Various processing techniques have been utilized to fabricate porous materials. Template synthesis is a commonly used technique in the preparation of porous materials [5]. Porous anodic alumina (PAA) is an attractive material as template due to its unique nanometric properties which are highly required in the world of nanotechnology [6]. Also, the PAA is used as a key material in optoelectronic systems and for replication processes. The fabrication of PAA is a cheap process, easy technology and high-throughput [7]. Many metals nanostructures were deposited on the PAA surface such as $\mathrm{Au}, \mathrm{Ni}, \mathrm{Ag}$ and $\mathrm{Zn}$ by different methods [8-11]. Among these methods, DC electrodeposition is widely employed to deposit nanostructures in PAA templates due to its inexpensive procedure [13, 14].

Chromium electroplating technology is widely used in various machinery equipment accessories to anticorrosion and the process of decorative technology due to the high hardness of coating, resistance to grind and other characteristics $[15,16]$. $\mathrm{Cr}$ as an element can be used in many fields including metallurgy, magnetic applications, catalysis and semiconductors [17-20]. Despite the important of the metallic nanoporous arrays because of their novel properties and potential applications, there are limited numbers of articles on the deposition of $\mathrm{Cr}$ nanoarrays because of the adhesion property of $\mathrm{Cr}$ atoms [21]. For these reasons, a facile method is presented to deposit $\mathrm{Cr}$ nanoporous film on a conductive substrate via the simultaneous etching of the PAA template. In addition the growth mechanism of the $\mathrm{Cr}$ nanostructures was discussed.

\section{Experimental Details}

Ordered porous anodic alumina (PAA) membranes were fabricated by a two-step anodization process. The aluminum foil (99.99\%) was electropolished in a mixture of $\mathrm{H}_{3} \mathrm{PO}_{4}$ and $\mathrm{H}_{2} \mathrm{SO}_{4}$ to improve surface smoothness. The first anodization of the electropolished $\mathrm{Al}$ foil was carried out in $0.3 \mathrm{M}$ oxalic acid electrolyte at a constant anodizing voltage of $50 \mathrm{~V}$ for 3 hours. After removing the aluminum oxide, the second anodization was carried out under the same conditions for $8 \mathrm{~min}$. The barrier layer was thinned by a successive drop of the DC voltage at rate of $0.1 \mathrm{~V} / \mathrm{s}$ from 50 to 15 . The layer finally maintained under DC voltage of $15 \mathrm{~V}$ for $15 \mathrm{~min}$. The pores of the membrane were widened by immersing the PAA in pore widening solution ( $6 \%$ wt phosphoric solution) for $45 \mathrm{~min}$.

The DC electrodeposition of chromium was carried out in a two electrode electrochemical cell. The anode was a Pt plate while the cathode was a PAA substrate. For the electrodeposition of $\mathrm{Cr}$ films, the electrolytic bath contained $\mathrm{CrO}_{3}(250 \mathrm{~g} / \mathrm{l})$ and $\mathrm{H}_{2} \mathrm{SO}_{4}(1 \mathrm{ml} / \mathrm{l})$ in double distilled water [22]. It should be noted that $\mathrm{H}_{2} \mathrm{SO}_{4}$ is widely used as a catalyst in the industrial $\mathrm{Cr}$ electrodepositing process [23-25]. Simultaneously, this $\mathrm{H}_{2} \mathrm{SO}_{4}$ is used as an etching solution for the walls of PAA. The electrodeposition was carried out at high current density $0.04 \mathrm{~A} / \mathrm{mm}^{2}$ and at temperature of $60{ }^{\circ} \mathrm{C}$. 
The fabricated PAA membranes and Cr nanostructures were characterized by using a scanning electron microscope and energy dispersive X-ray spectroscopy (EDX).

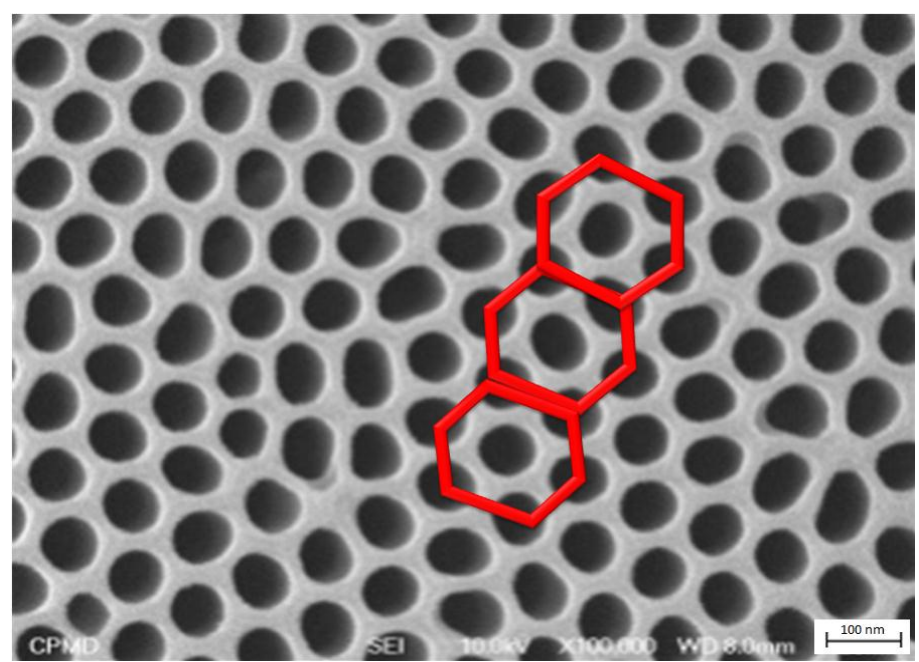

Fig. 1 shows top view SEM image of membrane anodized for $8 \mathrm{~min}$ and pore widened for $45 \mathrm{~min}$.

\section{Results and discussion}

Figure 1 shows a typical top view SEM of PAA membrane anodized for 8 min and pore widened for 45 min. The figure shows a typical hexagonal and smooth alumina nanoporous array with interpore distance of about $105 \mathrm{~nm}$, pore diameter of about $79 \mathrm{~nm}$ and pore density of about $1.2 \times 10^{11} \mathrm{~cm}^{-2}$.

The $\mathrm{Cr}$ electrodeposition was carried out at high current density of $0.04 \mathrm{~A} / \mathrm{mm}^{2}$ and at temperature of $60{ }^{\circ} \mathrm{C}$ using $\mathrm{CrO}_{3}(250 \mathrm{~g} / \mathrm{l}) / \mathrm{H}_{2} \mathrm{SO}_{4}(1 \mathrm{ml} / \mathrm{l})$ electrolyte. During the DC electrochemical deposition, the pores of the PAA were widened due to the presence of $\mathrm{H}_{2} \mathrm{SO}_{4}$ in the electrolyte as shown in Fig. 2. This figure describes a process of forming aluminum oxide nanowires from the common PAA membrane by $\mathrm{H}_{2} \mathrm{SO}_{4}$ and using over etching during $\mathrm{Cr}$ electrodepositing process. The evidence for this comes from the top view and cross-sectional view SEM images. The SEM images show nanowires of $\sim 200 \mathrm{~nm}$ long. This means that with this etching time, the minimum length is $200 \mathrm{~nm}$. During this etching time, the barrier layer at the bottom of some pores will be etched completely to allow the deposition of $\mathrm{Cr}$ on $\mathrm{Al}$ substrate.

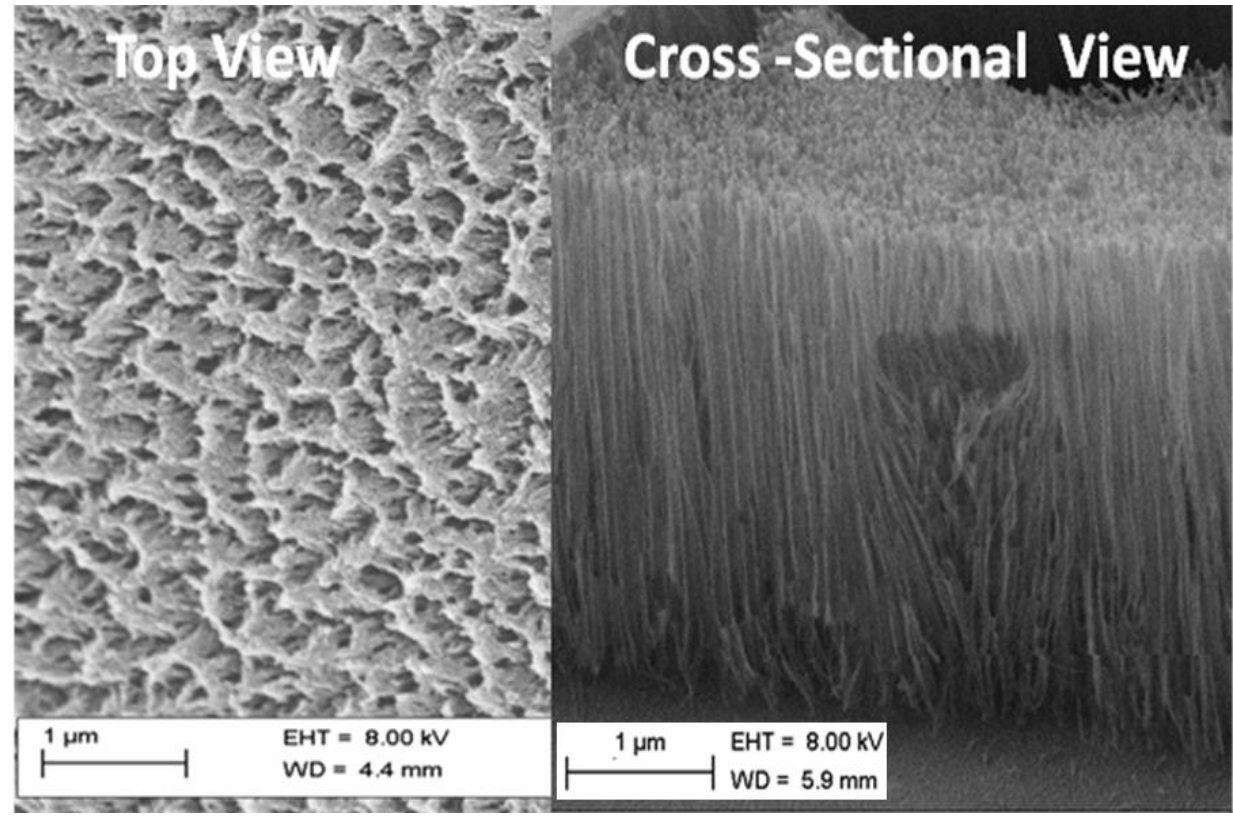

Fig. 2 shows top view and cross-sectional SEM images of PAA membrane widened during the $\mathrm{Cr}$ electrochemical deposition to form 2D alumina nanowires. 


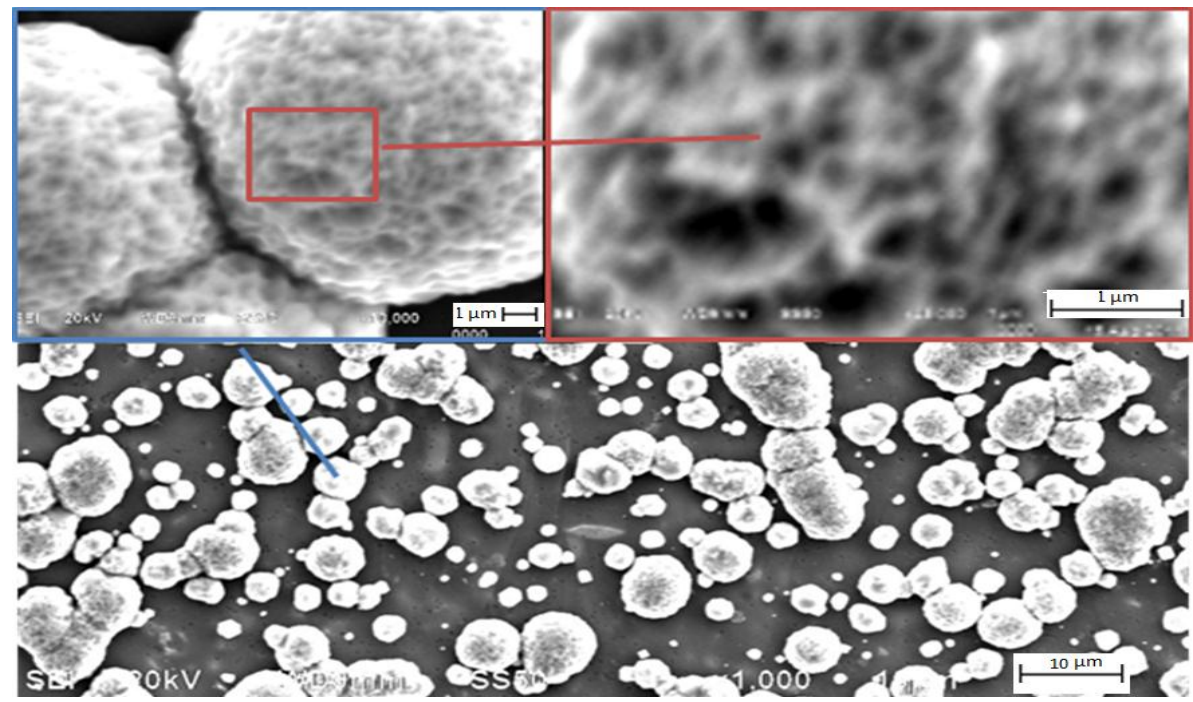

Fig.3 shows top view SEM images of nanoporous $\mathrm{Cr}$ particles formed at the upper part of the sample (air/electrolyte interface).

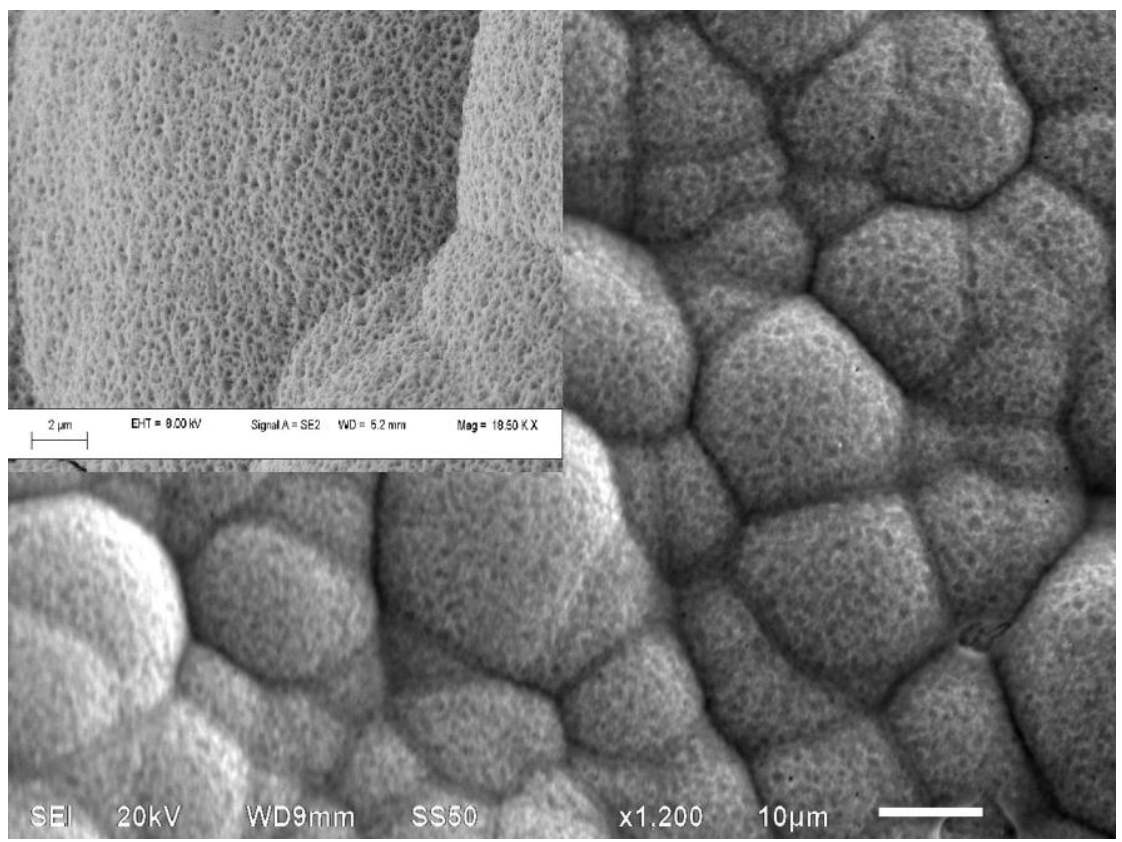

Fig.4 shows top view SEM images of nanoporous Cr film formed at the bottom part of the sample (inside the electrolyte).

The electrodeposition process allowed the thickness of the Cr layer to be increased gradually from top to bottom and the morphology to be changed from area to another. Figure 3 shows the morphology of the $\mathrm{Cr} / \mathrm{PAA}$ nanostructure at the upper part of PAA (interface air/electrolyte) at different magnification. This figure shows the growth of $\mathrm{Cr}$ particles on the substrate. Nano and micro $\mathrm{Cr}$ particles are distributed randomly on the substrate and separated by voids. These particles have spherical shapes with different sizes. The Cr particles have rough surface and contain nanopores of different diameters with irregular shapes.

Figure 4 shows the morphology of the $\mathrm{Cr}$ film at the bottom part of the sample (inside the electrolyte) at different magnification. Continuous $\mathrm{Cr}$ thin film was produced on the $\mathrm{Al}$ substrate. The $\mathrm{Cr}$ film is formed as a result of agglomeration of micro-stones of nanoporous surface. The nanoporous stones are of irregular shapes and the boundaries between these stones are clearly observed. By increasing the deposition time, the number of $\mathrm{Cr}$ stones is increased and the sizes of the $\mathrm{Cr}$ stones are increased. Then, for long depositing time, the $\mathrm{Cr}$ stones are grown until the particles are touched to form large sized-particle and in turn to form a continuous nanoporous $\mathrm{Cr}$ film. The film surface is not uniform and composed of different sized domains. 


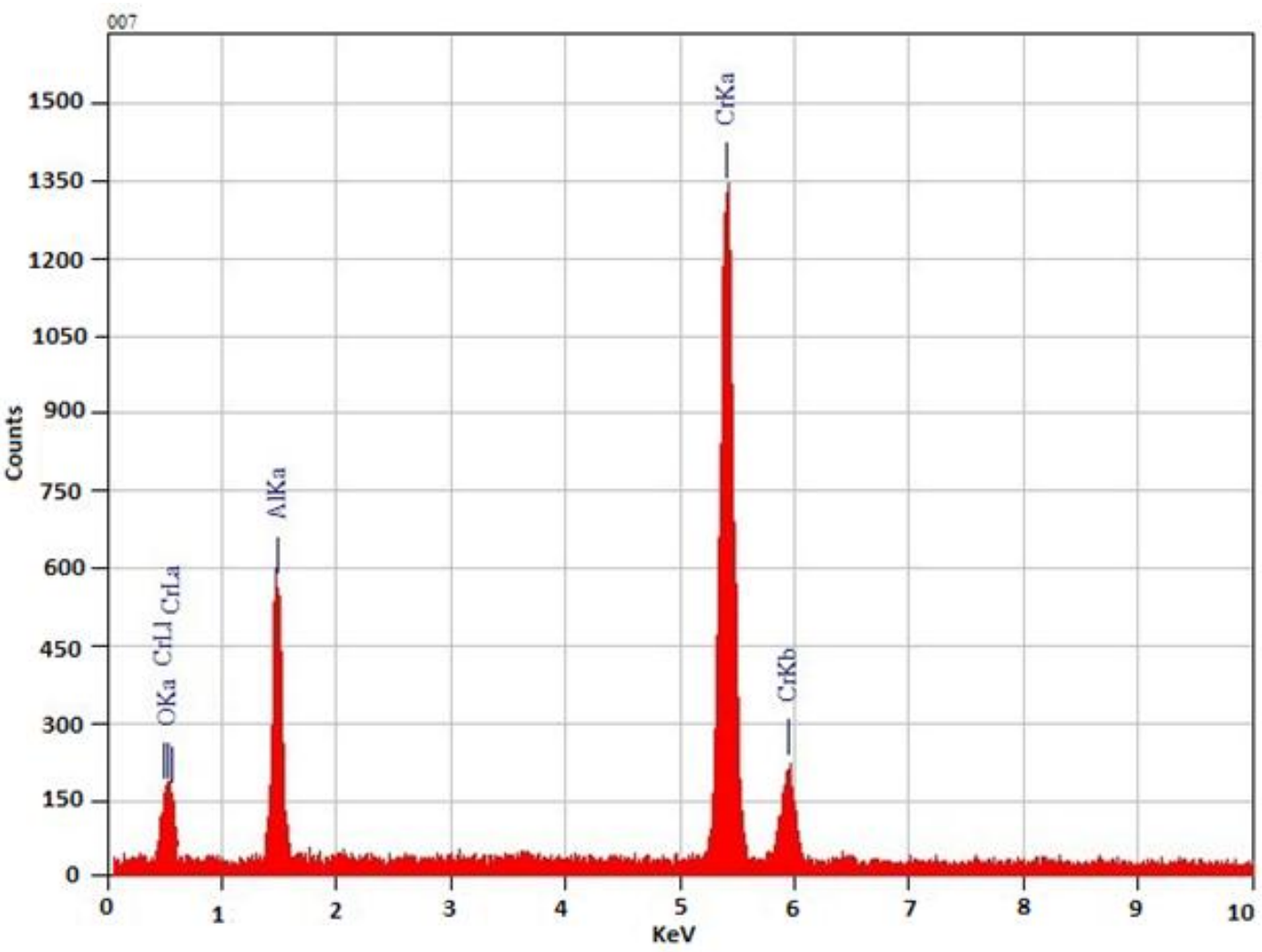

Fig. 5 illustrates EDX spectrum of the fabricated $\mathrm{Cr}$ film.

In order to check the chemical composition of the fabricated sample, the Cr/PAA film was analyzed by EDX as shown in Fig. 5. The EDX pattern shows the signals of $\mathrm{Cr}, \mathrm{Al}, \mathrm{O}$ and $\mathrm{C}$ elements. The quantitative results were $66.26 \% \mathrm{Cr}, 20.76 \% \mathrm{Al}, 5.89 \% \mathrm{O}$, and $7.09 \% \mathrm{C}$. The carbon microcontent came from the oxalic electrolyte that is used in the anodization process [26]. The observation of $\mathrm{C}$ and $\mathrm{O}$ in the EDX indicates the presence of the $\mathrm{C}_{2} \mathrm{O}_{4}^{-2}$ anions in the PAA [27].

The growth mechanism of the nanoporous $\mathrm{Cr}$ film on $\mathrm{Al}$ substrate by electrodeposition via PAA membrane was presented in Fig. 6 and suggested to be as follow:

As shown in Fig. 6(a), PAA consist of hexagonal cells, each surrounding a cylindrical pore grown perpendicularly to the initial aluminum surface [28, 29]. The cell of PAA is composed of two different layers [30-33]: (a) the inter layer which makes up the common internal walls between the pores, it is relatively pure alumina and (b) the outer layer which surrounding the pore, it content alumina and negative ion impurities $\left(\mathrm{C}_{2} \mathrm{O}_{4}{ }^{-2}\right.$ and $\left.\mathrm{OH}^{-}\right)$. The two layers of inner and outer oxides exist not only in the wall but also in the barrier layer at the pore bottom [30]. The outer oxide layer with anion-incorporated alumina is more prone to be etched under etching process, but inner layer is more resistant [34].

When the $\mathrm{Cr}$ electrolyte diffuses into the pores, sulfuric acid will ionize many $\mathrm{H}^{+}$ions to react with alumina membrane intensely according to the chemical reactions [35].

$$
\begin{aligned}
& \mathrm{H}_{2} \mathrm{SO}_{4} \rightarrow \mathrm{H}^{+}+\mathrm{HSO}_{4}^{-} \\
& 6 \mathrm{H}^{+}+\mathrm{Al}_{2} \mathrm{O}_{3} \rightarrow 2 \mathrm{Al}^{3+}+3 \mathrm{H}_{2} \mathrm{O}
\end{aligned}
$$

Then the interpore region between two neighboring pores is totally dissolved whereas the corner region (juncture of three neighboring pores) is partially dissolved because it is the thickest portion of alumina [35]. The remains parts at the corners of the cells induce the formation of alumina nanowires [28], as shown in Fig. 6(b). Actually the alumina nanowires inclined and aggregated into disordered domains due to the gravity field [34].

During deposition, $\mathrm{Cr}$ ions will be attracted by the anion impurities $\left(\mathrm{C}_{2} \mathrm{O}_{4}^{-2}\right.$ and $\left.\mathrm{OH}^{-}\right)$in the pore walls of PAA [30, 36]. Thus, it can be expected that $\mathrm{Cr}$ nuclei should preferably deposited around the alumina nanowire because of localized negative charges. As the deposition time increased, $\mathrm{Cr}$ nano/micro particles are grown as a result of the $\mathrm{Cr}$ migration and agglomeration. The nano/micro $\mathrm{Cr}$ particles are randomly distributed on the Al substrate with different sizes because the barrier layer is totally dissolved at some positions and partially dissolved at others. 

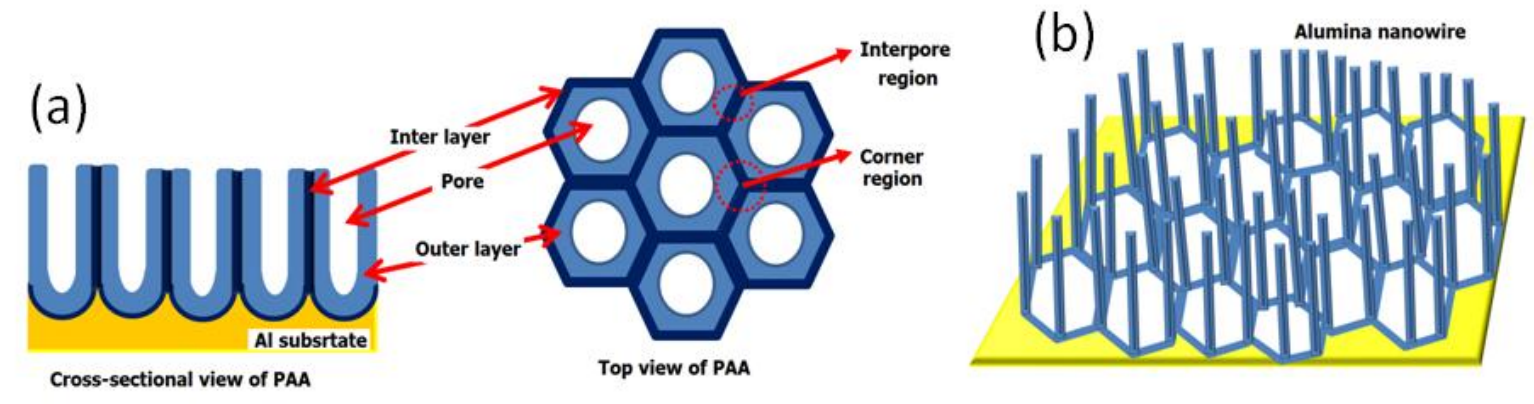

(c)

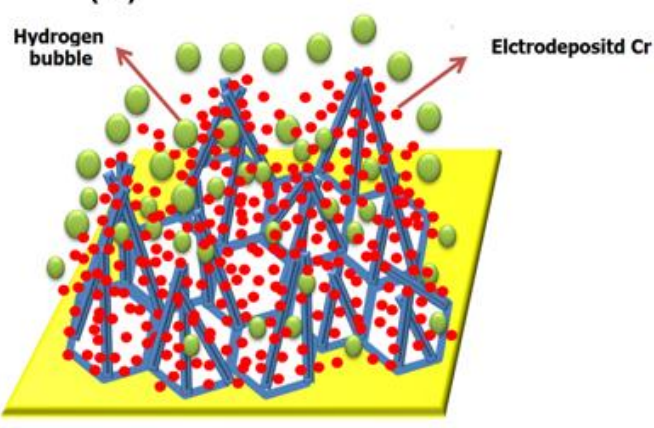

(d)

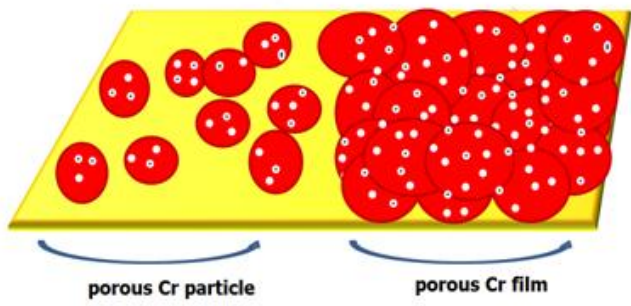

Fig. 6 illustrates a schematic diagram of the growth mechanism of nanoporous $\mathrm{Cr}$ film.

Concurrently with $\mathrm{Cr}$ deposition, hydrogen bubbles are arising from $\mathrm{H}^{+}$reduction at totally dissolved barrier layer regions of the (PAA/Al) cathode and escape from the surface as $\mathrm{H}_{2}$ gas [37, 38]. At high current density, large number of hydrogen bubbles is created on the PAA/Al substrate during the Cr deposition (Fig. 6(c)). The $\mathrm{Cr}$ particles are grown around the hydrogen bubbles and these bubbles leave marks such as pores when they escape towards the electrolyte/air interface as $\mathrm{H}_{2}$ gas.

In the same time, axial etching of the alumina nanowires occurs and directed from the top surface towards the $\mathrm{Al}$ substrate. After etching the alumina nanowires, nanopores of small diameters appear in the $\mathrm{Cr}$ particles. For long time deposition, the barrier layer is removed completely, more $\mathrm{Cr}$ ions are deposited. Then the sizes of the $\mathrm{Cr}$ particles increased and the grown particles are agglomerated to form large sized- particle and in turn to from of a continuous Cr thin film (Fig. 6(d)).

\section{Conclusion}

$\mathrm{Cr}$ nanoporous film has been deposited on Al substrate by using DC electrochemical deposition. Nanoporous Cr particles of rough surfaces and different sizes are firstly formed on the Al substrate. During the growth of $\mathrm{Cr}$ particles, two sets of pores of different sizes are formed inside the $\mathrm{Cr}$ microstones. The first set is attributed to the concurrent generation of hydrogen bubbles with extremely fast metal deposition at high current density. The second type results from the axial etching of the content alumina nanowires of the $\mathrm{Cr} / \mathrm{Al}_{2} \mathrm{O}_{3}$ composite and the nanopores developed toward the bottom. After $45 \mathrm{~min}$, the microstones are agglomerated to form continuous nanoporous $\mathrm{Cr}$ film. The fabricated $\mathrm{Cr}$ nanoporous film with extremely high effective surface area will be suitable for catalysis and sensing applications.

\section{References}

[1] F. Tang, H. Fudouzi, T. Uchikoshi, Y. Sakka, Preparation of porous materials with controlled pore size and porosity, J. Eur. Ceram. Soc. 24 (2004) 341-344

[2] F. Hoffmann, M. Cornelius, J. Morell, M. Fröba, Silica-based mesoporous organic-inorganic hybrid materials, Angew. Chem. Int. Ed. 45 (2006) 3216-3251.

[3] Y. Ueno, T. Horiuchi, M. Tomita, O. Niwa, H-S. Zhou, T. Yamada, I. Honma, Separate Detection of BTX mixture gas by a microfluidic device using a function of nano-sized pores of mesoporous silica adsorbent, Anal. Chem. 74(20) (2002) 5257-5262.

[4] H.D. Quan, M. Tamura, J. Murata, R.X. Gao, A. Sekiya, Fluorination of etheric substrates adsorbed on porous aluminium fluoride by gaseous fluorine, J. Fluorine Chem.106 (2000) 121-125.

[5] S.A. Johnson, P.J. Ollivier, T.E. Mallouk, Ordered Mesoporous Polymers of tunable pore size from colloidal silica templates, Science 283 (1999) 963-965.

[6] H. Masuda, K. Fukuda, Ordered metal nanohole arrays made by a two-step replication of honeycomb structures of anodic alumina, Science 268 (1995) 1466-468. 
[7] H. Chick, J.M. Xu, Nanometric superlattices: non-lithographic fabrication, materials, and prospects, Mater. Sci. Eng. R 43 (2004) $103-138$.

[8] W. Lee, M. Alexe, K. Nielsch, U. Gösele. Metal Membranes with Hierarchically Organized Nanotube Arrays. Chem. Mater. 17 (2005) 3325-3327.

[9] T.N. Narayanan M.M. Shaijumon, P.M. Ajayan M.R. Anantharaman. Synthesis of high coercivity core-shell nanorods based on nickel and cobalt and their magnetic properties, Nanoscale Res. Lett. 5 (2010) 164-168.

[10] N. Woosung, S. Hyejin, P. Sung Chan, B. Chang Hyun, N. Sang Hwan, P. Seung Min, H. Jeong Sook, Fabrication of nanodot arrays on Si by pulsed laser deposition using anodic aluminum oxide nanopore membrane as mask, Jpn. J. Appl. Phys.43 (2004) 77937797.

[11] C. Cheng, J. Lin, Y. Chen, Fabrication and growth mechanism of metal ( $\mathrm{Zn}, \mathrm{Sn}$ ) nanotube arrays and metal (Cu, Ag) nanotube/nanowire junction arrays, Mater. Lett. 62 (2008) 1666-1669.

[12] H. Lu, K. Yan, J. Yan, J. Wang, Fabrication of micro-Ni arrays by electroless and lectrochemical depositions with etched porous aluminum template, Bull. Mat. Sci. 33 (2010) 641-645.

[13] R.R. Singh, D. Painuly, R.K. Pandey, Synthesis and characterization of electrochemically deposited nanocrystalline CdTe thin films, J. Mat. Chem. Phys. 116(1) (2009) 261-268.

[14] J. Morales, L. Sanchez, S. Bijani, L. Martínez, M. Gabás, J.R. Ramos-Barrado: Electrodeposition of Cu ${ }_{2} \mathrm{O}$ : An excellent method for obtaining films of controlled morphology and good performance in Li-Ion Batteries, Electrochem. Solid-State Lett. 8 (3) (2005) A159-A162.

[15] L. Wang, K.S. Nam, S.C. Kwon, Effect of plasma nitriding of electroplated chromium coatings on the corrosion protection C45 mild steel, Surf. Coat. Technol. 202 (2007) 203-207.

[16] M. Zhao, S. Wu, P. An, J. Luo, Y. Fukuda, H. Nakae, Microstructure and corrosion resistance of a chromium-free multi-elements complex coating on AZ91D magnesium alloy, Mat. Chem. Phys. 99 (2006) 54-60.

[17] M.J. Udy, Chromium: metallurgy of chromium and its alloys, Reinhold, New York 2 (1956).

[18] D. Qian, G.L. Liu, D. Loison, G.S. Dong, and X.F. Jin, Growth and structure of Cr thin films on GaAs (0 01$)$, J. Cryst. Growth 218 (2000) 197-200.

[19] R.D. Tilley, D.A. Jefferson, Synthesis of chromium, nickel and chromium-nickel alloy nanoparticles, J. Mat. Chem. 12 (2002) 3809-3813.

[20] W.S. Zhang, E. Bruck, Z.D. Zhang, O. Tegus, W.F. Li, P.Z. Si, D.Y. Geng, K.H.J. Buschow, Structure and magnetic properties of Cr nanoparticles and Cr2O3 nanoparticles, Physica B 358 (2005) 332 -338.

[21] M. Shaban, H. Hamdy, F. Shahin, S. Ryu, Fabrication of ordered Cr nanostructures by self-agglomeration on porous anodic alumina membranes, J. Nanosci. Nanotechnol. 11 (2011) 7145-7150.

[22] V. Georgescu, C. Sirbu, N. Apetroaiei, Electrical and optical properties of Cr nano-crystal/silicon ultra-thin films prepared by electrodeposition, J. Optoelectron Adv. Mater. 8 (2006) 1456-1459.

[23] P. Leisner, G. Bech-Nielsen, P. Möller, Current efficiency and crystallization mechanism in pulse plating of hard chromium, J. Appl. Electrochem. 23 (1993) 1232-1236.

[24] A. Joshi, S.K. Kulkarni, Analysis of electrochemically deposited chromium films, J. Mater. Sci. 25 (1990) $1357-1365$.

[25] M. McCormick, S.J. Dobson, Characteristics and properties of electrodeposited chromium from aqueous solutions, J. Appl. Electrochem. 17 (1987) 303-314.

[26] I. Farnan, R. Dupree, Y. Jeong, G.E. Thompson, G.C. Wood, A.J. Forty, Structural chemistry of anodic alumina, Thin Solid Films 173 (1989) 209-215.

[27] D.H. Fan, G.Q. Ding, W.Z. Shen, M.J. Zheng. Anion impurities in porous alumina membranes: Existence and functionality, Micropor. Mesopor. Mater. 100 (2007) 154-159.

[28] Z.L. Xiao, Catherine Y. Han, U. Welp, H.H. Wang, W.K. Kwok, G.A. Willing, J.M. Hiller, R.E. Cook, D.J. Miller, G.W. Crabtree, Fabrication of alumina nanotubes and nanowires by etching porous alumina membranes, Nano Lett. 2 (2002) 1293-1297.

[29] F. Le Coz, L. Arurault, L. Datas., Chemical analysis of a single basic cell of porous anodic aluminium oxide templates, Mater. Charact. 61 (2010) 283-288.

[30] J. Choi, Y. Luo, R.B. Wehrspohn, R. Hillebrand, J. Schilling, U. Gösele. Perfect two-dimensional porous alumina photonic crystals with duplex oxide layers, J. Appl. Phys. 94(4) (2003) 4757-4762.

[31] G.E. Thompson, R.C. Furneaux, G.C. Wood, R.J. Hutchings, STEM/EDAX analysis of the cell walls in porous anodic films formed on aluminum, J. Electrochem. Soc.125(9) (1978) 1480-1482.

[32] K. Nielsch, J. Choi, K. Schwirn, R.B. Wehrspohn, U. Gösele, Self-ordering regimes of Pprous alumina, The 10 Porosity Rule Nano Letters 2 (7) (2002) 677-680.

[33] J.P. O'Sullivan, G.C. Wood, Proceedings of the Royal Society A 317 (1970) $511-543$.

[34] L. Yao, M. Zheng, L. Ma, W. Li, M. Li, W. Shen, Self-assembly of diverse alumina architectures and their morphology-dependent wettability, Mater. Res. Bull. 46 (2011) 1403-1408.

[35] G. Hu, H. Zhang, W. Di, T. Zhao. Study on Wet Etching of AAO Template, Appl. Phy. Res. 1 (2) (2009) $78-82$.

[36] G.Q. Ding, W.Z. Shen, M.J. Zheng, D.H. Fan, Synthesis of ordered large-scale ZnO nanopore arrays, Appl. Phys. Lett. 88 (2006) 103106-103109.

[37] C.A. Snavely, Transactions Electrochemical Society 92 (1948) 537-577.

[38] C. Bergenstof Nielsen, P. Leisner, A. Horsewell, On texture formation of chromium electrodeposits, J. appl. electrochem. 28 (1998) $141-150$ 